\title{
The Dynamics and Challenges of Distance Education at Private Higher Institutions in South Ethiopia
}

\section{Mulatu Dea Lerra}

Educational Planning and Management, Wolaita Sodo University, Ethiopia

Volume 2, Number 1/2015

DOI prefix: 10.18034/ajhal

Licensed:

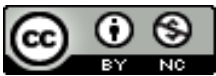

Source of Support: Nil

Conflict of Interest: Declared

Email for correspondence: lerramulee2010@gmail.com

\section{ABSTRACT}

Evidently, the implementation of a DL system does not ensure a high-quality education. The purpose of this study is to explore the dynamics and challenges of distance education at Private Higher Institutions in South Ethiopia. In a given study, a representative sample of tutors and academic program leaders selected through simple random and stratified sampling techniques. Questionnaires and interview were instrumental for data collection. The finding revealed that, the number of learners in a class during tutorial programs is not to the standard, the tutors' are responsible for one to two courses at a time and the remainder for more than two courses, assignments were too difficult for the ability of the students on the courses some learners do not receive modules before tutorial sessions and, consequently, some were forced to share modules, modules were not given long enough in advance of the actual tutorial sessions less commitment of stakeholders to realize the DL program. It is recommended that, Intensification distance education units at the institution and ensuring that students have a suitable educational background when they join to the specific program would make distance education efficient. In addition to this, it is good to try to make the system more flexible and use different information and communication technologies to support distance education.

\section{Key Words: Distance education, Distance Learning, Perception}

\section{INTRODUCTION}

As a force contributing to social and economic development, open and distance learning is today one of the most rapidly growing fields of education and training. It is fast becoming an accepted and indispensable part of the mainstream of educational systems in both developed and developing countries, with particular importance for the latter (UNESCO, 2000a).

Immense attention is given to open and distance learning to meet the educational needs of the adult population, with a view to providing new and alternative learning opportunities for those who were initially deprived of them, or who, for one reason, or another, did not make use of them. UNESCO (2005) continues to strengthen the role of open and distance learning in the diversification of educational delivery systems, remarkably, for technical 
and vocational education, encouraging co-operation and partnership between enterprises, professional bodies and distance teaching institutions. Support is also given to open and distance learning to meet the needs of the disabled, migrants, cultural and linguistic minorities, refugees, populations in crisis situations, who cannot be efficiently reached by traditional delivery systems.

The potential benefits of distance learning to the development of higher education is fully recognized and supported by UNESCO. In their efforts to make wider use of distance education to expand access to advanced learning and improve its efficiency, private institutions are assisted, among other things, by providing them with support in the initiation and development of open university schemes and other higher education programs making use of distance education.

The commitment to sustaining its private institutions to make wider use of open and distance learning, Ethiopian government gives priority to national capacity-building essential to the establishment and management of efficient open and distance learning systems (Yilfashewa, 2008)

Distance education has gained wide acceptance as one of the successful modes of extending education in a context of reach, acceptance, and productivity. As a scholar, reach in a sense that it has been instrumental in addressing the educational needs of speckled communities in different continents (Mitchell, 2009); acceptance in the sense that it has emerged "as a viable alternative delivery system and an alternative to the conventional system" (Rao, 2006:225); and productivity in the sense that "Research \& Development in this area has contributed in many ways to more general educational research and development." (Spector, 2009:160). The provision of an opportunity to learn without being restricted by geographical or time constraints is a major factor behind the growth of distance education programs.

Distance education highly essential to shares the goals of conventional education, aims at providing access to historically under-served, and highly motivated population provide students' freedom and program flexibility, offer useful learning opportunity to recipients at a time and local environment convenient to them, the delivery medium plays a crucial role in minimizing the gap between teaching and learning (Keegan, 1996). Distance education, according to Valery and Lord (2000), may offer four different benefits to education providers: enabling access to students; alleviating capacity constraints; capitalizing on emerging market opportunities and serving as a catalyst in institutional transformation.

Federal Republic of Nigeria (2004) the national policy of education document clearly stated that, the goal of distance education should be to: provide access to quality education and equity in educational opportunities for those who otherwise would have been denied, meet special needs of employers by mounting special certificate courses for their employees, encourage internationalization especially of tertiary education curricula, ameliorate the effect of internal and external brain drain in tertiary institutions by utilizing experts as teachers regardless of their locations or places of work (p. 45).

Since the education systems of most countries or areas have expanded quickly, these institutions have suffered from a poor understanding of quality and a lack of educational standards and indicators, (Cheng \& Tam, 1997). Consequently, there is a strong emphasis on the pursuit of education quality in ongoing educational reforms in both local and international contexts.

Development of distance learning courses needs good market research and business planning where a quality-based approach is a necessity, not a luxury (Lawton \& Barnes, 
1998). However, understanding of pedagogical issues in the distance education realm is a requirement to create a quality distance courses.

As Cooke \& Veach, (1997), the production and initial distribution of learning materials and the management of the student/lecturer interface using tools that permit the tracking of assignments and response times are important aspects of distance education.

Effectiveness, technology, student characteristics, and instructor characteristics, institutional support, and supervision emerged as six key success factors for distance education delivery (Valery \& Lord, 2000).

Mazzarol et al (2003) claim that, though the Higher Education Institutions (HEI) offering twinning programs focus increasingly on the market, their administrators, managers, and academic staff still faces significant challenges in terms of effectiveness. In addition, Ethiopian private universities have been affected by drastic supervision activities and deteriorating infrastructures in teaching and research facilities over the past two decades (Kargbo, 2002).

This paper presents a study of Southern Ethiopian Private Universities. The aim of this study is to explore the dynamics and challenges of distance education at private higher universities facing in the delivery of distance education program. The study at hand has paramount importance in exploring the achievements and challenges that may debilitate the system, enables us to consider the views of tutors and coordinators and students/learners towards the program and its practical implications for extending and strengthening the system. In addition to the above, the findings related to a given study have a broader application about introducing adaption's in the area under consideration. Specifically, it will provide some valuable suggestions and recommendations for the implementer and users such as students, counselors, teachers, educational administrators, curriculum designers and distance education coordinators.

\section{Statement of the Problem}

Open and Distance Learning as an educational method and a philosophical construct has been identified as the most potent instrument for combating the educational problems overwhelming notion like Ethiopia (Marew, 2002). Despite the splendid role and increased popularity of the open and distance learning, the quality of higher education via distance education has been called to question (Helland, 2002).

Different people perceive the advantages of DL differently and their perceptions have influenced attitudes towards the acceptance and use of DL in the system in our country and elsewhere. Out of the various problems facing distance education today, a very important one is how it is perceived by the individuals involved in it (Arnould, Price \& Zinkhan, 2002). Equally important as Gagne and Shephered, (2001), assessing problems on accurate perception of the sector by beneficiaries and/or stakeholders is a crucial factor. This is because the success of the open and distance education system could be affected by how it's viewed by the individuals involved in it. Secondly, the tutors and other stakeholders' perceptions have an enormous effect on the successful implementation of the system.

It is clearly indicated that, the term 'perception' refers to the idea, a belief or an image one has as a result of how she or he sees or understands something (Arnould, Price \& Zinkhan, 2002). Perception is the way people sense and interpret the world around them. Moreover, Arnould, et al. (2002) explained that perceptions are results from acquisition, consumption and disposal of goods. While Kolesar \& Galbraith (2000) suggested that perceptions are a consumer's opinions and attitudes towards any products after purchasing them. 
Gagne \& Shephered, (2001) claimed that, perception of the distance learning system in the instructional process is influenced by an individual's beliefs about the advantage of distance education, for himself, as a student, an employer (whose employees are also distant learning students), or as an educational planner, desirous of providing solutions to educational problems.

Evidently, as Saade \& Bahli, (2005) the implementation of a DL system does not ensure a high-quality education. There are still many problems commonly related to technological factors, including issues of access, connection, internet familiarity, learning facilities, provision of support, actor's commitment, etc. Although the advancement of technology has overcome or minimized these obstacles, it seems that the problems have shifted to the learner's side when using a distance learning system. Learners may feel isolated and unmotivated (Saade \& Bahli, 2005). Hence, if distance learning is to overcome the many obstacles that students face, it is necessary to study the acceptance of DL from the students' perspective.

Much distances-learning professionals and academics acknowledge that DL is a simplified version of the teaching and learning method (Compeau \& Higgins, 1995). The use of innovative information and communication technology (ICT) has raised questions about the effectiveness of distance learning compared to the traditional classroom format.

Currently, the subject of much controversy is whether the proliferation of courses offered online and the way in which this technology is used has transformed the traditional classroom format into a DL environment (Arbaugh, 2000; Rovai \& Barnum, 2003). Thus, student acceptance of DL is one of the critical factors that should be evaluated in order to assess adequately whether the successful implementation of a DL system can support teaching-learning activities and the student experience (Martins \& Kellermans, 2004).

Distance learning researchers argue that there is a relationship between external factors (e.g., computer self-efficacy, technological factors, instructional design, and instructor's characteristics, facilities, support) and what are classified as DL acceptance factors (namely, perceived ease of use and perceived usefulness). Technical problems and a low level of students' technical skills are two top factors that DL researchers think pose the most significant barriers to distance learning (Muilenburg \& Berge, 2005).

Volery \& Lord, (2000) argued that, the characteristics of the instructor are important factors that appear to influence students' perception of DL. The successful implementation of DL does not only rely on advanced technology - it also relies on the characteristics of the instructor. The success of the DL model is determined by the instructor's ability to cultivate and maintain a certain level of collaborative learning activities and initiatives.

The instructor must also be a facilitator in DL, and this characteristic plays an important role in motivating and encouraging student learning. The interaction and communication between instructors and students are also an essential part of distance learning (Volery \& Lord, 2000).

A study conducted in India has discovered a lack of sufficient time, the difficulty of course materials and the absence of adequate learner support as the major perceived problems that caused the withdrawal of students from distance teacher-training programs (Koul, 1987).

Moreover, as Purnell (2003), the most frequently identified barriers in DL included; lack of technical support, lack of adequate library and its equipment, lack of administrative support, the amount of preparation time required to create assignments, and student resistance.

To be effective, distance learning programs need to address several issues seeking appropriate and timely decisions on the nature of educational program and their learning strategies, their use of technology and equipment, their dealing with students' and 
instructors' concerns, and organizational, governance, and financial matters (Hall, 1979; Valentine, 2002).

Furthermore, Berge (2002:182) observes that, "impediments to teaching and learning at a distance can be: situational; epistemological; philosophical; psychological; pedagogical; technical; social; and/or cultural."

The local study of Yilfashewa (2008) stated that, for smooth and efficient delivery of distance education programs, a good administrative and financial setup, support to learners, facilities are very important. She strongly argued that, this was lacking at the private higher institutions.

There was not only a lack of commitment at the actor's sides but also inherent weaknesses in the form of bureaucratic procedures, inefficiencies, poor communication, and isolated decisions. Further, there was a lack of attention as well as a result of the lack of clarity in the authority-responsibility relationship for the management and coordination of the program (Yilfashewa, 2008)

Recent and rapid technological advancements and developments raise questions whether distance education practice has kept pace with new, affordable applications and the changing educational needs of a learning society. Based on the above-aforementioned challenges the researcher want to explore the dynamics and challenges of distance education at the Southern Ethiopia private institutions. Thus, the following guiding question were formulated and properly treated.

- What are the perception of stakeholders (tutors, coordinators, students) to ward the distance education at private institutions in the Southern region?

- To what extent the private higher institutions stakeholders committed to the proper support and realization of distance education program in their respective Universities?

- What are the major challenges of distance education program of private higher institutions at the respective universities?

\section{Research Design and Methodology}

\section{$>$ Subjects}

The population for a given study was made up of distance education participants in the Southern part of Ethiopia private institutions (Wolaita, Hawassa, Arba Minch, Hossana). Both tutors and the academic program coordinators, FGD members were part of the study. Probability sampling techniques (simple random and stratified sampling techniques ) were instrumental under this study). The researcher finally decided 40 tutors, and 10 program leaders/coordinators and 6 distance learners as FGD as the total elements of the sample.

\section{$>$ Data Collection Tools}

For the specific kind of investigation, only questionnaires (for tutors) and interview (for program leaders) was used. Furthermore, an attempt to obtain valuable information, FGD with distance learners and the practical and personal observations of the investigator were also included as additional input to consolidate and crosscheck the data obtained through the aforementioned tools. Meanwhile, document was used as sources of evidence to substantiate the finding should not be overlooked. 


\section{$>$ Methods of Data Analysis}

The data was analyzed using different statistical techniques. Both qualitative and quantitative approaches were employed in analyzing and interpreting the data. Moreover, the only statistical methods used for quantitative data was a descriptive and inferential statistics. The researcher believes that the descriptive and inferential statistics would have the advantage to indicate the dynamics and challenges of distance education at private higher institutions in South Ethiopia in combination with the qualitative information as perceived by participants.

\section{RESULTS AND DISCUSSION}

\section{Table 1: Demographic Characteristics of the Respondents}

The researcher has distributed and successfully collected 40 questionnaires for tutors of the University/ University college to have adequate information regarding distance education practices. Below are the demographic characteristics of the respondents in terms of qualification, year of service, sex. Since the sample size is less that hundred, the researcher has opted to put figures in number and percentages.

Table 1: Demographic Charateristics of the Respondents

\begin{tabular}{|c|c|c|c|c|c|c|c|c|c|c|c|c|c|}
\hline \multicolumn{6}{|c|}{ Qualification Types } & \multicolumn{4}{|c|}{ Sex } & \multicolumn{4}{|c|}{ Service Year } \\
\hline \multicolumn{2}{|c|}{ B.A/B.SC } & \multicolumn{2}{|c|}{ MA/MSC } & \multicolumn{2}{|c|}{$\mathrm{PhD}$} & \multicolumn{2}{|c|}{ Male } & \multicolumn{2}{|c|}{ Femal } & \multirow{2}{*}{\multicolumn{2}{|c|}{$\frac{<=5 \text { years }}{\text { No }}$}} & \multirow{2}{*}{\multicolumn{2}{|c|}{$\begin{array}{c}>5 \text { years } \\
\%\end{array}$}} \\
\hline No & $\%$ & No & $\%$ & No & $\%$ & No & $\%$ & No & $\%$ & & & & \\
\hline 16 & 32 & 31 & 62 & 3 & 6 & 43 & 86 & 7 & 14 & 38 & 76 & 12 & 24 \\
\hline
\end{tabular}

The above table revealed that about 62 percent of the tutors hold MA/M.Sc degrees. The remaining 32 percent of the respondents were qualified first degree level. No respondents appointed as tutors who had a Ph.D. However, the researcher's personal observations revealed that three $\mathrm{Ph}$.D holders included in the sample were appointed as tutors in the area of Hawassa and Arba Minch. According to the results shown in the table, only 14 percent of the tutors were females, and the majority of the respondents are experienced instructors with length of service of more than five years. It is concluded that, although the qualifications of tutors appears to be suitable, their knowledge of DL methodology is insufficient and not satisfactory. This situation could have an adverse effect on the teaching and learning process and lead to lack of productivity since the unique feature of the DL system demand specific types of tutors with specialized training.

The results of an interview depict how the tutors and learners perceive and share experiences of tutorial classes and tutors. The majority of the stakeholders strongly agreed that tutorial classes, though are not being regularly held by expert tutors, are very helpful to them. Both the coordinators, tutors and learners claimed that the allocated time for and the number of tutorial classes was not sufficient to cover the syllabus. The tutors and some learners, of course, underlined the need for making the tutorial classes compulsory. The majority of center coordinators and FGD groups accredited the cooperation of the tutorial class coordinators and tutors. They, however, suggested that the tutors should be given training on DL system at private higher institutions. The center coordinators responded in the interview sessions that, the commitment of stakeholders (tutors, learners) toward the proper realization of the distance education is insufficient. 
Figure 1: Number of Distance Learners/Tutees in a Class, Number of Courses, Number of Assignments

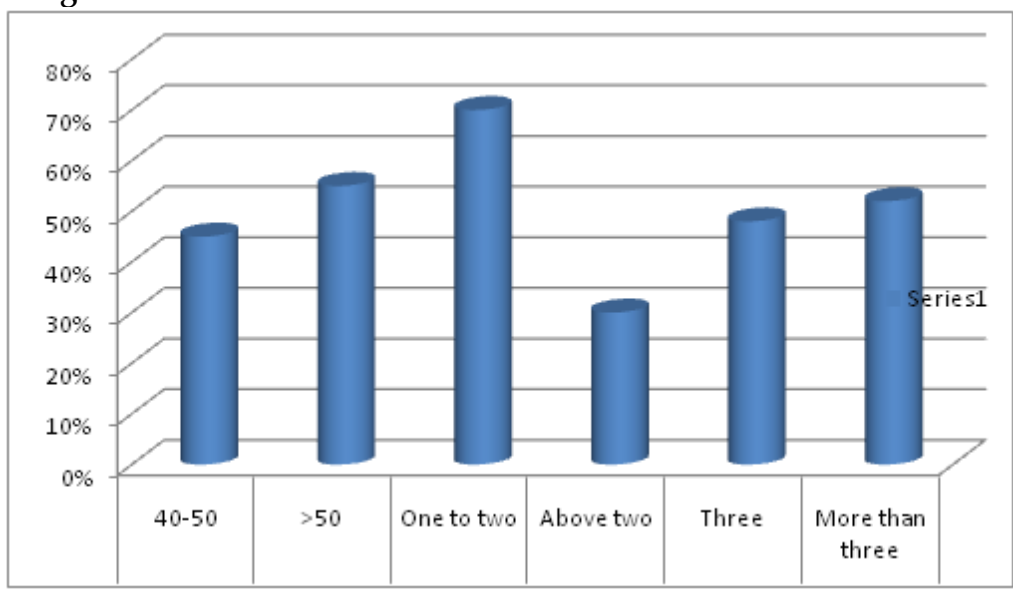

As the figure 1 shows that, as experienced by 55 percent of the respondents, the number of learners in a class during tutorial sessions is not up to the standard that is more than 40 . A distinctive feature of the DL education system is an interaction with other learners and tutors during tutorial sessions. In order for this to be implemented effectively, the number of students in the class needs to be reduced to the standard. The table also reveals that about 70 percent of the respondents are responsible for two courses at a time and the remainder for more than two courses. It is clear that this, in turn, makes instructors responsible for the corresponding assignments and tutorial classes. Experience in this regard showed that it was not advisable for tutors to take more than two DL courses at a time.

With the same token, about 52 percent of the respondents highlighted the fact that they were responsible for correcting more than three separate assignments. Although the content of assignments varies from course to course, it is difficult, if not impossible, to be responsible for more than three or four different assignments at a time.

Table 2: The Level of Difficulty of the Courses Modules and Assignments

\begin{tabular}{|c|c|c|c|c|c|c|c|c|c|}
\hline \multirow{3}{*}{$\begin{array}{l}\text { Difficulty Level of } \\
\text { Course Modules }\end{array}$} & \multirow[t]{2}{*}{$\mathrm{N}$} & \multicolumn{4}{|c|}{ Difficult } & \multicolumn{4}{|c|}{ Moderate } \\
\hline & & Mean & St.D & $\mathrm{F}$ & $\operatorname{sig}$ & Mean & St. D & $\mathrm{F}$ & Sig \\
\hline & 40 & 3.43 & 1.07 & 0.480 & 0.790 & 3.87 & 0.48 & 0.883 & 0.51 \\
\hline $\begin{array}{l}\text { Difficulty Level of } \\
\text { the Assig. }\end{array}$ & 40 & 3.26 & 1.23 & 1.864 & 0.104 & 3.79 & 0.49 & 0.206 & 0.958 \\
\hline
\end{tabular}

As the table depicts, the majority of the respondents described the level of difficulty of course modules and corresponding assignments as "moderate" with the mean value of (3.87) and St Dev. (0.48) and the mean of (3.79) St D of (0.49) respectively with the significance level of (0.51. However, some of the respondents rated them as "difficult" with the mean value of (3.43) and St. Dev of (1.07) and the mean of (3.26) St D of (1.23) respectively with the significance level of (0.958). The ability levels of the majority of distance learners should be taken into consideration during the preparation of the course modules and assignments. This fact was also highlighted an interview with coordinators and FGD groups from Distance learners. 
With regards to the assignment, tutors' in responded that, the assignments submitted are poorly organized, and in some case redundant and irrelevant questions are incorporated. There is no enough time to give feedback to students. The assignments are prepared by the module writers and are often unsuitable about content coverage, and the preparation and organization of assignments be poor. There are too many questions set for some courses, and the assignments were not submitted on time. Students were not conscientious about completing the assignments. It is observed that students copy the assignment answers from each other. Moreover, the handwriting was often not legible, and it was timeconsuming to read and scored properly. Delay of submission of the assignment and lack of guidance given to trainees about the assignment are a few of the problems of the current distance education system. Some of the questions are ambiguous and complex for students, and some of the questions for the assignments are not clear.

Furthermore, the communication problem, poor English, inattentiveness towards their education and lack of confidence, lack appropriate time management skills, overloaded due to their private work on top of the program, were among the major challenges of distance learners. Students are interested to attend tutorial sessions given by their tutors, but the majority of distance education learners' lack motivation for learning.

Distance learners come to the tutorial sessions without prior reading their learning modules. Lack of skills for active participation, and being registered solely for the sake of improving their career prospects. The learners expect their tutors to cover everything in tutorial sessions with them in a single tutorial class. The center coordinators are not properly trained to pay attention to problems such as, lack of information on the tutorial time/ schedule, too far residence from the tutorial center, lack of time to study the material in advance of tutorial sessions and absenteeism from the tutorial sessions for unknown reasons also other critical challenges of distance learning. To sum, most students were not motivated to learn, but they come because they were forced to do so. Many of them need further assistance and help which may not be possible during tutorial sessions alone.

Figure 2: Mean Distribution of Responses on the Patterns of Timely Module Distribution

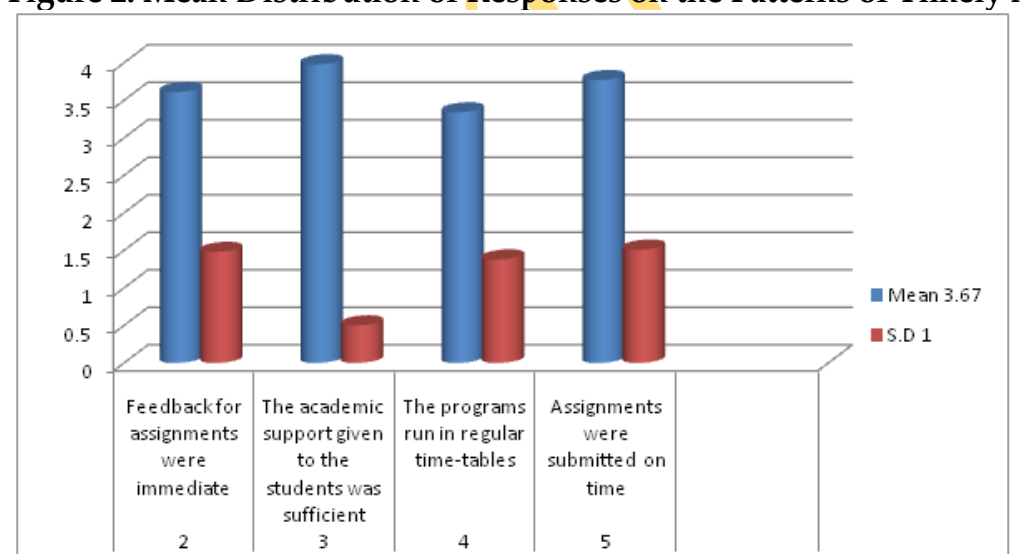

In terms of timely module distribution, figure 2 revealed that it was positive. However, some of the respondents highlighted the fact that some learners did not receive modules before tutorial sessions, did not have the necessary modules for the semester and were forced to share modules on certain courses with the mean value of $(3.34,2.23)$ and St Dev. of $(1.48,1.24)$ respectively. Furthermore, some of the respondents complained that tutors 
did not even receive modules on time for some courses to which they were assigned the mean value of (3.21) and St. Dev of (1.44). This caused inevitable delays regarding preparation by tutors of effective tutorial sessions. Similarly, about majority of the total respondents replied that modules were not provided well in advance of tutorial sessions with the mean value of (3.89) and St Dev. of (1.05). Tutors need to have the module weeks or even months before the actual tutorial session take place to be able to prepare well. A face to face interview with coordinators disclosed that this happens partly due to organizational problems and partly due to the reluctance on the part of tutors.

Table 3: Mean Distribution on Response Status of Tutorial Support to Distance Learners

\begin{tabular}{|c|l|c|c|}
\hline \multirow{2}{*}{ No } & Items /Components & \multicolumn{2}{|c|}{ Tutors $\mathrm{N}=40$} \\
\cline { 3 - 4 } & & Mean & S.D \\
\hline 1 & Individualized academic supports was adequate & 3.67 & 1.00 \\
\hline 2 & Feedback for assignments were immediate & 3.61 & 1.48 \\
\hline 3 & The academic support given to the students was sufficient & 3.98 & 0.50 \\
\hline 4 & The programs run in regular time-tables & 3.34 & 1.38 \\
\hline 5 & Assignments were submitted on time & 3.77 & 1.51 \\
\hline
\end{tabular}

With regards to supports of distance learners in the above table 3 revealed that, all in all, the respondents clearly rated the support services as "poor." The majority of the subjects responded that the academic support provided is insufficient and the assignments were not submitted on time with the mean value of (3.98) and St. Dev of (0.50). Similarly, all in all of the respondents highlighted the fact that there was no standard timetable for running the DL program. It is not good practice for any educational program implemented without organizing a timetable of activities for each component. Disappointingly, all of the respondents felt that the feedback on the assignments was not immediate and individual support was inadequate with the mean value of 3.61 and 3.67 respectively. The personal observations of the researcher also revealed that these areas were faced deep rooted problems.

Figure 3: Mean distribution on Responses toward the Effectiveness of the Distance Education Program

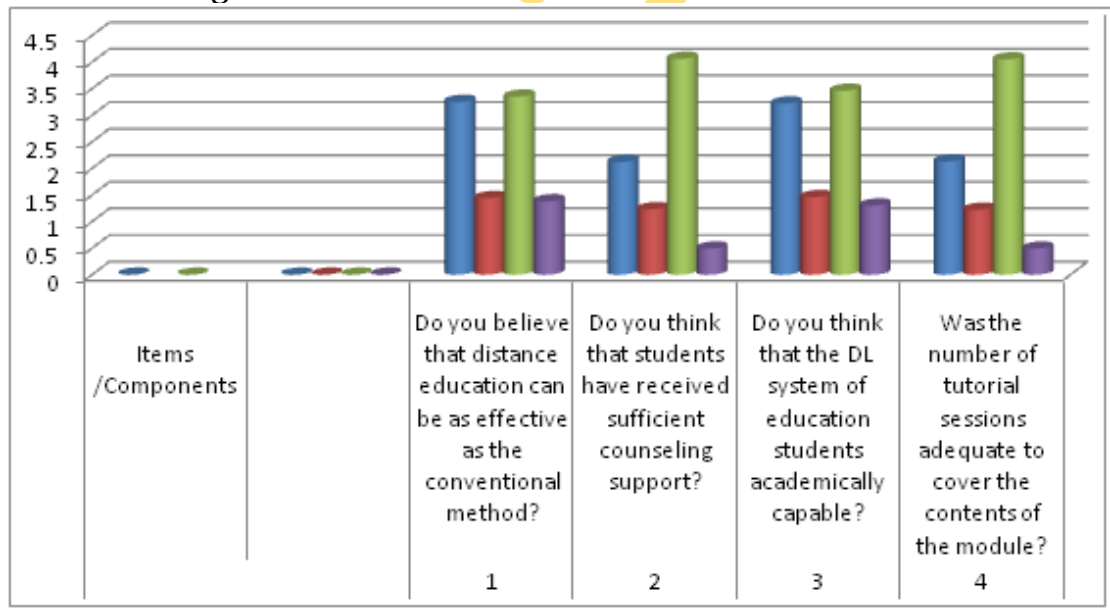


Figure 3 below depicts the effectiveness of the distance education program and capability of learners at private higher institutions. As far as the effectiveness of distance education program is concerned, the respondents were asked to reflect on whether they believed DL to be as effective as the conventional education system or not. Some of the respondents with the mean value of (3.25) think that it is as effective as the conventional system. However, the majority of respondents with the mean value of (3.35) have reservations whether the quality of the DL education system is equal to that of the conventional system.

With the same token, some of the respondents believe that distance education learners are as competent as conventional learners with the mean value of (3.22). A large proportion of the respondents think that distance education learners are less able with the mean value of (3.46). The table also reveals with the mean value of (4.06); the respondents feel that the counseling support arranged for the distance education learners is inadequate. Furthermore, majority of the respondents with the mean value of (4.05) are of the opinion that the time allotted to cover the content of the learning module is insufficient. The personal observations of the researcher and FGD of distance learners also uncovered the fact that coordinators and program organizers seem to have insufficient knowledge regarding allocation of time for tutorial sessions. As a result, many tutors experience the problems mentioned by the respondents.

With regards to academic competency of distance learners, tutors' responded that, the academic background of the students was not up to standard. Some of them were too old to be students. Apart from a few exceptions, most of the distance learners were not prepared to participate fully in the class, and the level of academic performance was lower compared to a conventional (regular) students. Since some students did not possess the appropriate prior qualification, they lacked motivation and showed little effort and achievement. Some did not read the modules because they were incapable of doing so.

The other challenges of distance education on behalf of the government is that it does not pay attention to distance education and there is a lack of appropriate incentives for those who complete courses which could demotivate possible future students. Hence, lack of appropriate attention to the program by the concerned bodies should be the special feature of DE. In the current DL, lack of appropriate academic support for individual candidates, problems of module distribution at the appropriate times, lack of academic feedback before the final (term-end) exam, failure to assess needs and workload, and poor or not well prepared/ organized learning modules are among the critical problems of DE.

Moreover, poor relationship between administrative regions, zones, woredas education offices and institutions responsible for distance education, lack of appropriate support for the learners and lack of organized study centers, institutions reluctance to open new programs through distance education, frequent changes of policy, poor coordination of the program and little attention paid to tutors are still the common feeling of tutors as a major challenges.

Distance education is becoming the option of academically poor and weak candidates. Respondents suggested that poor communication and orientation of students who join the distance education program, poor quality of the program in terms of students, tutors and materials, lack of time and libraries at the study centers, insufficient module supply, wrong location of study centers, heavy workloads of tutors', lack of policy and proper organizational structure, and lack of information in distance education program in general need great attention to augment the level of performance of students in DL. 


\section{CONCLUSIONS AND THE WAY FORWARDS}

\section{Conclusions}

The researcher intended to investigate the dynamics and challenges of distance learning in the South Ethiopia Private institutions. A descriptive survey approach was then employed as the method of the study, and representative sample of tutors' and academic program leaders was selected using a probability sampling technique. To triangulate the research results in the researcher used observation, FGD and document analysis. The researcher decided that 40 tutors and 10 program coordinators and 6 FGD distance learners became the sources of information. Questionnaires, interviews, personal observations and documentary analysis and FGD were the instruments employed to gather the required data. The major findings of this study can be recapitulated as follows:

As we know the crucial factors to the success of Distance Education programs is the perception of tutors, coordinators, learners, office staff and others towards quality of support services. The study witnessed that the selected tutors and learners had positive perception of the distance education program and academic supports while some of the learners had experienced the problems of depositing the admission and other fees into the bank. The tutors claimed that the amount and payment of their honorarium is insufficient and discouraging and that may demotivate the tutors. With the same token, majority of the respondents (Tutors and learners) made serious complaints about the delivery time of the materials supplied to them. The respondents also expressed dissatisfaction over the, the limited number of the tutorial class, and the delay in result publication. The learners had conflicting perception about the location of examination center and tutorial center. Meanwhile, the commitment of the stakeholders) tutors and center coordinators) to the proper realization of the distance learning program in the private higher institutions are unsatisfactory.

The number of learners in a class during the tutorial programs is not to the standard, the tutors' are responsible for one to two courses at a time and the remainder for more than two courses, assignments were too difficult for the ability of the students on the courses some learners did not receive modules before tutorial sessions or even the entire semester and, consequently, some were forced to share modules on certain courses, modules were not given long enough in advance of the actual tutorial sessions. In terms of the provision of the fundamental tutorial services, the tutorial programs were perceived to be poor by the majority of respondents. The types of services provided by tutors are not compatible with the fundamental principles of a distance education system, feedback on the assignments was not immediate and individual support services were inadequate and finally the conventional system of education in a superior position to distance education in terms of the acquisition of knowledge and skills, the effectiveness of face-to-face instruction over the distance mode of delivery as well as in terms of the systematic organization and implementation of educational programs. The nature of the tutorial services provided by tutors does not follow the fundamental principles of distance education. The tutorial programs were devoted largely to teachers' verbal explanation of descriptive facts that are the typical feature of a conventional face-to-face instruction.

\section{$>$ The Way Forwards}

Intensification distance education units in an institution and ensuring that students have a suitable educational background when they join to the specific program would make distance education more effective. In addition to this, it is good to try to make the system more flexible and use different information and communication technologies to support the distance education program. Distance learners though outreach geographically, situation should be appropriate to keep them closer at least by providing them with all possible facilities that the regular program/ learners have access to. That is, proper counseling, 
tutorials, continuous assessment, library service and the like need to be provided in time. Modules should be prepared and distributed at the appropriate time. To seriously undertake the program in a well-organized manner, students should be evaluated appropriately, and the process of grading of student performance should be taken seriously. In general, proper policy, awareness raising, good organization and well-considered utilization of man power would make the distance education program effective and efficient.

The increase in the number of tutorial centers, allotment of enough time, enhancement of the promotion service offered, and well-organized learning modules are all necessary preconditions for launching any given distance education program. Good course is structuring, effective management of the program, attractive pay for tutors, as well as better awareness and support from education bureau would make distance education more successful and attractive. There should be the transformation of methodology from a teacher-dominated formal lecture to a learner-centered pedagogical approach. Awareness creation on the program details to tutors is important, and fundamental principles of the methodology are, therefore urgently required. Frequent and continuous evaluation, limiting overstretching of tutors with regard to workload and feedback on assignments would make the program more effective. It is indicated that the most important strategies are to plan, implement, monitor and update the way we offer the training.

Above all, it is important to constantly gather data from the students on what they need and prefer, the problems they face and what they want to be done for them. Unless we do this, we cannot attain what we want from distance education. It would be wise to use various types of communication media to augment the effectiveness of distance education. Devising procedures to force learners to do assignments by themselves would increase the academic performance of the learners and assure the quality of distance education. Standardization of the learning modules should be given priority to safeguard the reputation of the distance education system. In addition to this, the appointing of suitably qualified and trained tutors could raise the standard of the open and distance education system.

\section{REFERENCES}

Arnould, E.J., Price L.L., \& Zinkhan G.M. (2002), Consumers. Chicago, IL: McGraw- Hill.

Berge (2002). Obstacles to distance training and education in corporate organizations. Journal of Workplace Learning, 14 (5), 182-189.

Cheng, C. \& Tam, W. M. (1997). Multi-models of quality in education. Quality Assurance in Education, 5(1), $22-31$.

Cooke, J. \& Veach, I. (1997). Enhancing the learning outcome of university distance education: an Australian perspective. International Journal of Educational Management, 11 (5), 203-208.

Enakrire, T. R. \& Onyenania, O. G. (2007). Factors affecting the development of information infrastructure in Africa. Library Hi Tech News, 2, 15-20.

Federal Republic of Nigeria (2004). National policy in education (4th ed.). Lagos: NERDC Press.

Gagne. M, and Shephered, M. ( 2001). A comparison between a distance and traditional graduate accounting class.T.H.E journal 28(9). Retrieved From http:/ / www.thejournal.com/magazine/vault/A3433.cfm

Hall, J. W. (1979). Administration of external degree programs. Peabody Journal of Education, 56(3), $186-194$.

Helland, K. (2002). Perception of Distance Learning and the Effects on Selection Decision. Retrieved from http:/ / bus.utk.edu?iopsyc/pdf/Perception-of-Distance- Education-siop2003.pdf

Kargbo, J. A. (2002). African universities and the challenge of knowledge creation and application in the information age. Library Review, 51 (8), 411.

Khan M. Education and Health Status of Child Workers of Dhaka City Global Disclosure of Economics and Business. 2014;3(2):16-23.

Kolesar, M.B., \& Galbraith, R.W. (2000). A services-marketing perspective on e retailing: Implications for eretailers and directions for further research. Internet Research : Electronic Networking Applications and Policy, 10 (5), 424-438 
Koul, B. N. (1987). A study of Dropouts: Implications for Administrative and Educational Strategies. New Delhi, Unpublished paper.

Lawton, S. \& Barnes, R. (1998). Developing distance learning courses in a "traditional" university. Quality Assurance in Education, 6 (2), 106-111.

Marew, Z. (2002). The Impact of Globalization on Distance Education. The Ethiopian Journal of Educational researchers' Association. Volume 1, No. 1.

Martins, L. L. \& Kellermans, F. W. (2004). A Model of Business School Student's Acceptance of a Web- Based Course Management System. Academy of Management Learning and Education, 3(1), 7-28.

Mazzarol, T., Soutar, G. N. \& Seng, M. S. Y. (2003). The third wave: future trends in international education. The International Journal of Education Management, 17 (3), 9099.

Mitchell I. M. (2009).Distance Education: An International Journal: reflections on how it all began. Distance Education, 30(1):143-156.

Mitiku W, Alemu Y and Mengsitu S. 2014. Challenges and Opportunities to Implement Inclusive Education Asian Journal of Humanity, Art and Literature, 1, 118-135.

Muilenburg, L. Y., \& Berge, Z. L. (2005). Student barriers to online learning: A factor analytic study. Distance Education, 26(1), 29-48.

Rahman, M. (2014). Students Matriculation Factors for Higher Education in Private Universities of Bangladesh. Global Disclosure Of Economics And Business, 1(1), 54-64. Retrieved from http://ischolar.in/index.php/GDEABC/article/view/54509

Rao, S. S. (2006). Distance education and the role of IT in India. The Electronic Library, 24 (2), 225-236.

Rovai, A.P. and Barnum, K.T. (2003). On-Line Course Effectiveness: An Analysis of Student Interactions and Perceptions of Learning. Journal of Distance Education, 18(1), 57-73.

Saade, R. \& Bahli, B. (2005). The Impact of Cognitive Absorption on Perceived Usefulness and Perceived Ease of Use in On-line Learning: an Extension of the Technology Acceptance Model. Information and Management, 42, 317-327.

Spector, J. M. (2009), Reconsidering the notion of distance in distance education. Distance Education. 30(1): $157-161$.

Sultana M. 2014. Ethics in Teaching Profession ABC Journal of Advanced Research, 3, 44-50.

UNESCO (2000a): The Dakar Framework for Action, Education for All: Meeting Our Collective Commitments, adopted by the World Education Forum Dakar, Senegal, 2628 April 2000, Paris: UNESCO

UNESCO (2000b): Analytical survey, Distance Education for the Information Society,Policies, Pedagogy and Professional Development, UNESCO Institute for Information Technologies in Education, Moscow: UNESCO/IITE

UNESCO (2005): Final Report, World Education Forum (Dakar, Senegal), Paris: UNESCO

Valentine, D. (2002). Distance learning: promises, problems, and possibilities. Online Journal of Distance Learning Administration, 5(3), 1-11.

Volery, T. \& Lord, D. (2000). Critical success factors in online education. The International Journal of Educational Management, 14 (5), 216-223.

Yilfashewa Seyoum (2008). Stakeholders' perceptions and concerns on open and distance education in the higher institutions: The case of Eastern Ethiopia. Turkish Online Journal of Distance Education-TOJDE April 2008 ISSN 1302-6488 Volume: 9 Number: 2 Article

This article is is licensed under a Creative Commons AttributionNonCommercial 4.0 International License. Attribution-NonCommercial (CC BYNC) license lets others remix, tweak, and build upon work non-commercially, and although the new works must also acknowledge \& be non-commercial.

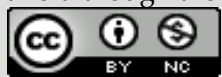

How to Cite: Lerra MD. 2014. The Dynamics and Challenges of Distance Education at Private Higher Institutions in South Ethiopia Asian Journal of Humanity, Art and Literature, 2, 9-22. 


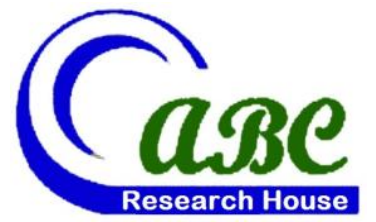

- Off Pantai Dalam, Kuala Lampur, Malaysia

- Road \# 4, Shyamoli, Dhaka-1207, Bangladesh

- 3900 Woodhue Place, Alexandria, VA 22309, USA

www.abcreorg.weebly.com / www.abcjournals.net

Asian Business Consortium (ABC) is a multi-disciplinary research, training, publishing, digital library supporting and service house. Though founded in 2010 as the Business and Computing organization of Asia, it was reconstituted as the ABC in 2011. It has been working for creating and nurturing talents in USA, Malaysia and Bangladesh since its inception. The objectives of consortium are solely centered round the welfare and humane attitude of the founders who enthusiastically took up this noble cause and materialized it with a view to promote research and educational activities for the encouragement of scholars to develop their knowledge, to publish their analysis oriented scientific researches in international Journals, books, the task of organizing workshops, seminars, conferences, training, personality development programs and allied services.

In addition to research activities, $\mathrm{ABC}$ provides a good number of scholarships to the poor and meritorious students at various levels of education throughout the world. It plays an important role in the field of research by funding research projects and publishing the research papers. This consortium will unquestionably become the mouth-piece of the dark horses and unacknowledged scholar whose endowed and commendable contributions shall be provided an outlet keeping in mind the greater good of the larger society of the world.

$A B C$ runs the following international referred journals for creating a platform to share the thoughts of professionals, scholars and academicians throughout the world.

\section{ABC Publications (ABC Journals)}

- Asian Accounting and Auditing Advancement (4A Journal)

- Asian Business Review (ABR)

- Asian Journal of Applied Sciences and Engineering (AJASE)

- Global Disclosure of Economics and Business (GDEB)

- $\quad$ ABC Journal of Advanced Research (ABC-JAR)

- International Journal of Reciprocal Symmetry and Theoretical Physics (IJRSTP)

- American Journal of Trade and Policy (AJTP)

- Asian Journal of Humanity, Art and Literature (AJHAL)

- Malaysian Journal of Medical and Biological Research (MJMBR)

- Asia Pacific Journal of Energy and Environment (APJEE)

- $\quad$ Engineering International (EI)

- $\quad$ ABC Research Alert (Online)

Each journal home page provides specific information for potential authors and subscribers. Open access policy, the quick review process, rich editorial boards and quality publications have already made ABC Journals unique. ABC Journals are published under the direct supervisions of renowned academicians of the world.

Collaboration in Conference: $\mathrm{ABC}$ considers high-quality conference papers for publication. Please contact us for detailed information.

Collaboration in Publishing: If you like to start writing a book, propose a new journal or advertise in $\mathrm{ABC}$ journals, please feel free to contact us. 